\title{
Testing of SRS and RFETS Nylon Bag Material
}

by

J. E. Laurinat

Westinghouse Savannah River Company

Savannah River Site

Aiken, South Carolina 29808

This paper was prepared in connection with work done under the above contract number with the U. S.

Department of Energy. By acceptance of this paper, the publisher and/or recipient acknowledges the U.S. Government's right to retain a nonexclusive, royalty-free license in and to any copyright covering this paper, along with the right to reproduce and to authorize others to reproduce all or part of the copyrighted paper. 


\section{DISCLAIMER}

This report was prepared as an account of work sponsored by an agency of the United States Government. Neither the United States Government nor any agency thereof, nor any of their employees, makes any warranty, express or implied, or assumes any legal liability or responsibility for the accuracy, completeness, or usefulness of any information, apparatus, product, or process disclosed, or represents that its use would not infringe privately owned rights. Reference herein to any specific commercial product, process, or service by trade name, trademark, manufacturer, or otherwise does not necessarily constitute or imply its endorsement, recommendation, or favoring by the United States Government or any agency thereof. The views and opinions of authors expressed herein do not necessarily state or reflect those of the United States Government or any agency thereof.

This report has been reproduced directly from the best available copy.

Available to DOE and DOE contractors from the Office of Scientific and Technical Information, P.O. Box 62, Oak Ridge, TN 37831; prices available from (615) 576-8401.

Available to the public from the National Technical Information Service, U.S. Department of Commerce, 5285 Port Royal Road, Springfield, VA 22161. 


\section{DISCLAIMER}

Portions of this document may be illegible in electronic image products. Images are produced from the best available original document. 
Testing of SRS and RFETS Nylon Bag Materials (U)

\section{By}

\section{J. E. Laurinat}

Issued: August 20, 1998

\section{Approvals}

Saner \& Lawnet

$8 \cdot 20.98$

J. E. Laurinat, Author, SMT/C\&HTS

Date

1on chekr $8 / 20 / 98$

N. M. Askew, Technical Reviewer, SMT/C\&HTS

Date

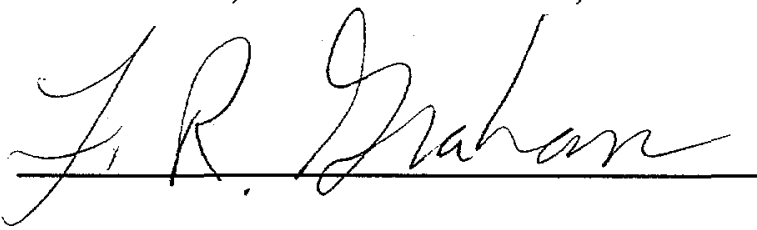

F. R. Graham, Responsible Manager, SMT/C\&HTS

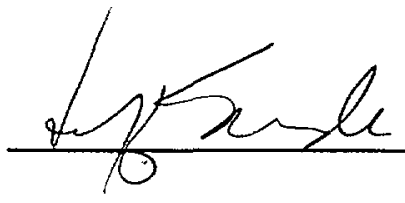

J. B. Schaade, NMS\&S Engineering

Date 
Table of Contents

Section

Page

1.0 Introduction and Summary ........................................................ 1-2

2.0 Measurement of the Effect of Irradiation on Material Properties ......... 2-3

3.0 Measurement of Outgassing due to Heating .................................... 3-4

4.0 Calculation of Outgassing due to Irradiation.................................... 4

5.0 Conclusions and Recommendations........................................... 4-5

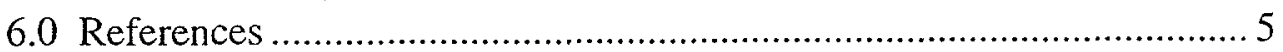

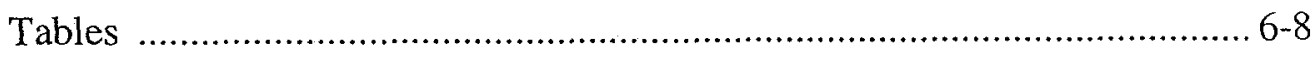

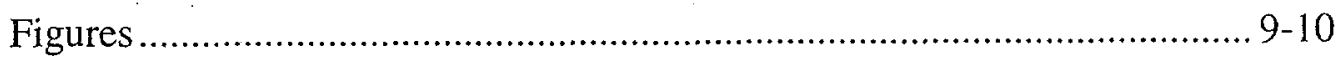

Appendix: Calculation of the Expected Dose and Gas Generation for Plutonium Can Bag Material ........................................... 11-12 


\subsection{Introduction and Summary}

This report compares the effects of radiation and heating on nylon bagout materials used at the Savannah River Site (SRS) and the Rocky Flats Environmental Technology Site (RFETS). Recently, to simplify the processing of sand, slag, and crucible (SS\&C), FBLine has replaced the low-density polyethylene (LDPE) and polyvinyl chloride (PVC) bags normally used to package cans of plutonium-bearing material with nylon bags. LDPE and PVC are not soluble in the nitric acid dissolver solution used in F-Canyon, so cans bagged using these materials had to be repackaged before they were added to the dissolver. Because nylon dissolves in nitric acid, cans bagged in nylon can be charged to the F-Canyon dissolvers without repackaging, thereby reducing handling requirements and personnel exposure.'

As part of a program to process RFETS SS\&C at SRS, RFETS has also begun to use a nylon bagout material. The RFETS bag materials is made from a copolymer of nylon 6 and nylon 6.9, while the SRS material is made from a nylon 6 monomer. In addition, the SRS nylon has an anti-static agent added. The RFETS nylon is slightly softer than the SRS nylon, but does not appear to be as resistant to flex cracks initiated by contact with sharp corners of the inner can containing the SS\&C. ${ }^{2}$

FB-Line Operations has asked for measurement of the effects of radiation and heating on these materials. Specifically, they have requested a comparison of the material properties of the plastics before and after irradiation, a measurement of the amount of outgassing when the plastics are heated, and a calculation of the amount of radiolytic gas generation. Testing was performed on samples taken from material that is currently used in FB-Line (color coded orange) and at RFETS. The requested tests are the same tests previously performed on the original and replacement nylon and LDPE bag materials. ${ }^{3,4,5}$

To evaluate the effect of irradiation on material properties, tensile stresses and elongations to break were compared for unirradiated and irradiated samples. A standard ASTM method for the measurement of tensile plastic properties ${ }^{6}$ was used. Properties were measured both parallel to the direction of machining (MD) and transverse to the direction of machining (TD). Tensile strength measurements showed that the ultimate strengths of the SRS replacement bag material decreased by $22 \%$ in the MD orientation and $17 \%$ in the TD orientation after irradiation with $5 \times 10^{6} \mathrm{rad}$, a dose equivalent to about 8-9 months exposure in a plutonium can. For the RFETS material, the decreases were $23 \%$ in the MD orientation and $56 \%$ in the TD orientation. Although the $5 \times 10^{6}$ dose significantly degraded the properties of both materials, their strengths remained superior to those previously measured for LDPE, ${ }^{4}$ even after irradiation.

Elongations to break also decreased, especially for the SRS material. The decrease for the SRS material were $86 \%$ in the MD orientation and $95 \%$ in the TD orientation. For the RFETS material, elongations to break decreased at least $18 \%$ in the MD orientation and $29 \%$ in the TD orientation.

When samples of both the SRS and RFETS materials were heated in a sealed container to the maximum expected storage can temperature of about $95^{\circ} \mathrm{C}$, they outgassed at 
pressures ranging from 16 to $22 \mathrm{psig}$. These pressure increases would not cause a can to fail. Using a representative $G$ value of 1.6 molecules $/ 100 \mathrm{ev}$, the amount of outgassing due to radiolysis was calculated to be negligible.

In conclusion, it may be stated that the results of the strength tests and the outgassing measurements and calculations demonstrate that the SRS and RFETS replacement bag materials are acceptable substitutes for LDPE with respect to mechanical properties.

\subsection{Measurement of the Effect of Irradiation on Material Properties}

To determine the effect of irradiation on bag strength, the SRS and RFETS nylon bag materials were irradiated to $5 \times 10^{6} \mathrm{rad}$ using a Cobalt-60 gamma source. As explained in the Appendix, these exposures are equivalent to the expected doses that the bag material would receive after sealing a plutonium can for a period of 8 to 9 months. The bags were irradiated at a rate of $2.71 \times 10^{4} \mathrm{rad} / \mathrm{hr}$ for 185 hours in air.

Irradiated and unirradiated samples were submitted to the SRTC Strategic Materials Technology Section for analyses of tensile properties. A standard ASTM test was used to measure the tensile strength. ${ }^{6}$ Elongations to break were also measured for both tests. The tests were performed using an Instron Model 1122 mechanical testing frame. Tensile test samples were stretched at a cross-head speed of $50 \mathrm{~mm} / \mathrm{min}$. Resistance to tear tests conducted during the previous bag material evaluation were not run this time because the plastic properties were out of the instrument measurement range.

Test samples were cut from blown sheets of material identical to those used or proposed for use in FB-Line. Figure 1 depicts the samples.

Table 1 reports the results of the tensile tests. Tensile test results include upper and lower yield loads, the ultimate load just prior to break, and elongation at break. Results are statistically analyzed in Tables 2 and 3. Table 2 also lists results of previous tensile tests of the unirradiated LDPE material. ${ }^{4}$ The statistical analyses show that both the SRS and RFETS nylons became weaker and significantly stiffer after irradiation. The elongation to break decreased by at least $18 \%$ in the machine direction and $29 \%$ in the transverse direction when the RFETS nylon was irradiated, while the SRS nylon lost virtually all of its ability to stretch when irradiated. (The unirradiated RFETS samples did not break even when stretched to the maximum extension limit of the Instron testing frame; the percentage decrease in elongation to break is calculated using the machine limit.) There was little if any decrease in yield loads for the irradiated samples. The ultimate loads, which were reached after a significant amount of stretching had occurred in the unirradiated samples, decreased by $22 \%$ in the machine direction and $17 \%$ in the transverse direction for the SRS nylon and by $23 \%$ in the machine direction and $56 \%$ in the transverse direction for the RFETS nylon, however. These results indicate that the irradiation had little effect on tensile strength up to the point of breakage. ${ }^{7}$ Instead, the main effect of irradiation was to increase the stiffness of the nylon. The increase in stiffness after irradiation is probably due to radiation-induced cross linking of the nylon fibers. 
Tensile strengths of both nylon materials remained equal or superior to those of unirradiated LDPE even after irradiation. The average ultimate loads for irradiated samples of the SRS and RFETS were 7.6 and $12.1 \mathrm{lbf}$ in the machine direction and 6.8 and $6.8 \mathrm{lbf}$ in the transverse direction, compared to average ultimate loads of $8.2 \mathrm{lbf}$ in the machine direction and $4.2 \mathrm{lbf}$ in the transverse direction for unirradiated LDPE.

\subsection{Measurement of Outgassing due to Heating}

A series of tests was conducted in which samples of the replacement bag materials were placed inside a closed vessel and heated to about $95^{\circ} \mathrm{C}$ inside a drying furnace. ${ }^{8}$

Pressures were measured by a 0-30 psig dial pressure gauge. The entire assembly, including the pressure gauge, was heated inside the furnace. Four tests were conducted, one test each with SRS and RFETS nylon samples, and two calibration tests, one with just air and another with a small amount of water in the vessel. Theoretically, the calibration tests should register increases equal to the sum of the water vapor pressure and the increase due to volumetric expansion. The two tests with the plastic samples should give equilibrium pressure increases equal to the sum of the increase from volumetric expansion and the vapor pressure of condensable gases released by the plastic at the test temperature. Thus, for a sufficiently large sample, the pressure generated by heating the plastic should not depend on the amount of plastic in the container. Relatively large samples were used to ensure that the vapor space became saturated with offgases from the plastic. SRS and RFETS nylon samples weighing 1.24 and 1.59 grams, respectively, were heated in the $25-\mathrm{cm}^{3}$ test chamber. The weight-to-volume ratios for these tests, 0.050 and 0.064 grams $/ \mathrm{cm}^{3}$, equal or exceed the estimated weight-to-volume ratios for a bag inside the plutonium can, which are $17.7 \mathrm{grams} / 631 \mathrm{~cm}^{3}$, or $0.028 \mathrm{grams} / \mathrm{cm}^{3}$ for the SRS material, and $17 \mathrm{grams} / 631 \mathrm{~cm}^{3}$, or $0.027 \mathrm{grams} / \mathrm{cm}^{3}$ for the RFETS material.

Figure 2 depicts transient pressure measurements for the outgassing tests. Comparisons between measured and expected results for the air and water vapor calibration tests demonstrate that these measurements are at least approximately correct. Theoretically, the equilibrium pressure for these tests should be the sum of the increase due to heating of the air initially in the vessel and the vapor pressure of water. The pressure for the air test should increase 3.5 psi due to the temperature increase from room temperature. For the water vapor test, there should be an additional 12.5 psi increase due to evaporation of water at the $95^{\circ} \mathrm{C}$ test temperature, for a total of $16.0 \mathrm{psi}$. The measured pressure rises were 2.4 psi for the air calibration test and 12.8 psi for the water vapor calibration test. The RFETS sample generated an equilibrium pressure increase of about $16 \mathrm{psi}$, and the SRS sample generated increases ranging from 17 to $22 \mathrm{psi}$. The pressures for the SRS material may have been high due to difficulties in controlling the temperature during that test; the temperatures ranged as high as $109^{\circ} \mathrm{C}$. The outgassing pressures do not exceed the allowable pressure for the outer container, which is 40 psig. ${ }^{9}$

The test results indicate that both plastic samples may have outgassed water vapor and perhaps a small amount of plasticizer. The outgassed vapor amounts to about one weight $\%$ of the samples, if it is assumed that it consisted primarily of water vapor. 
The results of these outgassing tests differ appreciably from previous results for the SRS nylon. ${ }^{5}$ The previous tests indicated that there was little if any outgassing. An increase in the water content of the nylon over time is the most plausible explanation for the differences between the two sets of results. All nylons absorb moisture from the environment, with some types absorbing more than others.

\subsection{Calculation of Outgassing due to Irradiation .}

The amount of outgassing from the nylon bag material due to irradiation has been calculated based on the irradiation level and an estimated G-value for gas generation. A calculation was performed in lieu of a measurement because the volume of gas that would be generated is too small to measure with existing site equipment. In a separate study, measurements under vacuum gave G-values ranging up to 1.6 molecules $/ 100 \mathrm{ev}$ for various types of nylon; ${ }^{10}$ this highest cited value is used in the calculations for both SRS and RFETS nylons. Two-thirds of the gas that was generated was hydrogen, and most of the remainder was carbon monoxide.

With an assumed G-value of 1.6 molecules/100 ev, a plutonium can bag is calculated to generate only about $1.7 \mathrm{~cm}^{3}$ of vapor in a service time of 1 year, based on a decay rate of $1 \times 10^{9}$ disintegrations $/ \mathrm{min} / 100 \mathrm{~cm}^{2}$. This volume is insignificant compared to the air space enclosing the bags between the inner and outer plutonium cans, so there should not be a significant pressure increase due to radiolytic outgassing. The volume between the two cans has been measured to be $631 \mathrm{~cm}^{3}$; the calculated radiolytic gas generation is only $0.3 \%$ of this total. The Appendix presents details of the calculation of the amount of gas generation.

\subsection{Conclusions and Recommendations}

To evaluate the effect of irradiation on material properties, tensile stresses and elongations to break were compared for unirradiated and irradiated samples, using standard ASTM methods for the measurement of tensile plastic properties and resistance to tear propagation. Properties were measured both parallel to the direction of machining (MD) and transverse to the direction of machining (TD). Tensile strength measurements showed that the ultimate strengths of the SRS bag material decreased by $22 \%$ in the MD orientation and $17 \%$ in the TD orientation after irradiation with $5 \times 10^{6}$ rad, a dose equivalent to about one year exposure in a plutonium can. The ultimate strengths of the RFETS bag material decreased by $23 \%$ in the MD orientation and $56 \%$ in the TD orientation. Although the $5 \times 10^{6}$ dose significantly degraded the properties of both materials, their strengths remained superior to those previously measured for LDPE, even after irradiation.

Elongations to break also decreased, especially for the SRS material. The decrease for the SRS material were $86 \%$ in the MD orientation and $95 \%$ in the TD orientation. For the RFETS material, elongations to break decreased at least $18 \%$ in the MD orientation and $29 \%$ in the TD orientation. 
When samples of both the SRS and RFETS materials were heated in a sealed container to the maximum expected storage can temperature of about $95^{\circ} \mathrm{C}$, they outgassed at pressures ranging from 16 to 22 psig. These pressure increases would not cause a can to fail. Using a representative $G$ value of 1.6 molecules/100 ev, the amount of outgassing due to radiolysis was calculated to be negligible.

In conclusion, it may be stated that the results of the strength tests and the outgassing measurements and calculations demonstrate that the SRS and RFETS replacement bag materials are acceptable substitutes for LDPE with respect to mechanical properties.

\subsection{References}

$\sim 1$. R. A. Pierce, "Testing of Acid-Soluble Plastics for SS\&C Processing in F-Canyon," SRT-CTS-96-0120, November 19, 1996.

/2. R. A. Pierce, "Dissolution of RFETS Nylon Bags," SRT-CTS-98-1022, May 14, 1998.

$\checkmark 3 . \quad$ M. J. Morgan, "Mechanical Properties of Irradiated Nylon," SRT-MTS-97-3012, July 15, 1997.

4. J. E. Laurinat, "Testing of Nylon Bag Material (U)," WSRC-TR-97-0244, Rev. 0, July $15,1997$.

$\checkmark$ 5. J. E. Laurinat, "Testing of Replacement Bag Material (U), WSRC-TR-98-0036, Rev. 0, February 24, 1998.

6. ASTM D638-89, "Standard Test Method for Tensile Properties of Plastics," Annual Book of ASTM Standards, Vol. 8.01, 1989.

7. M. J. Morgan and G. Chapman, "Mechanical Properties of Irradiated Nylon," SRT-MTS-98-3012, August 14, 1998.

8. J. E. Laurinat, Laboratory Notebook WSRC-NB-92-42, p. 154-156.

9. S. Fleischman, "Recommendations for the Resolution of Plutonium Storage Issues Outlined in 'Master Plan for Evaluating F-Area Stored Plutonium', NMP-EFB-93-0108," SRTC-CTS-93-0281, November 15, 1993.

10. M. Dole, ed., The Radiation Chemistry of Macromolecules, Vol. II, Academic Press, New York (1973), p. 122.

11. D. R. Lide, ed., CRC Handbook of Chemistry and Physics, 75th ed., CRC Press, Boca Raton (1995), p. 11-33.

12. D. R. Lide, ed., CRC Handbook of Chemistry and Physics, 75th ed., CRC Press, Boca Raton (1995), p. A-105. 
Table 1. Results of Individual Tensile Strength Tests

\begin{tabular}{|c|c|c|c|c|c|c|}
\hline Cut & $\begin{array}{l}\text { Dose } \\
\text { (RAD) }\end{array}$ & $\begin{array}{l}\text { Upper Yield } \\
\text { Load (lbf) }\end{array}$ & $\begin{array}{l}\text { Lower Yield } \\
\text { Load (lbf) }\end{array}$ & $\begin{array}{l}\text { Ultimate } \\
\text { Load (lbf) }\end{array}$ & $\begin{array}{l}\text { Elongation } \\
(\%)\end{array}$ & $\begin{array}{l}\text { Failure } \\
\text { Location }\end{array}$ \\
\hline \multicolumn{7}{|c|}{ SRS Nylon: } \\
\hline MD & None & 7.83 & 7.40 & 8.82 & 151 & grip \\
\hline MD & None & 9.08 & 8.59 & 9.08 & NA & reduced section \\
\hline MD & None & 6.45 & 6.42 & 11.35 & 244 & grip \\
\hline MD & None & 6.99 & 6.86 & 9.81 & 196 & shoulder \\
\hline $\mathrm{TD}$ & None & 8.39 & 8.04 & 8.51 & NA & shoulder \\
\hline TD & None & 8.16 & 7.59 & 8.16 & 63 & reduced section \\
\hline TD & None & 6.38 & 5.86 & 8.40 & 207 & reduced section \\
\hline $\mathrm{TD}$ & None & 6.73 & 6.23 & 7.39 & 153 & reduced section \\
\hline $\mathrm{TD}$ & $5 \times 10^{6}$ & 7.04 & $\mathrm{NA}^{*}$ & 7.04 & 8 & shoulder \\
\hline TD & $5 \times 10^{6}$ & 6.51 & $\mathrm{NA}^{*}$ & 6.51 & 6 & reduced section \\
\hline MD & $5 \times 10^{6}$ & 7.57 & $\mathrm{NA}^{*}$ & 7.57 & 22 & reduced section \\
\hline MD & $5 \times 10^{6}$ & 7.65 & NA* & 7.65 & 32 & reduced section \\
\hline \multicolumn{7}{|c|}{ RFETS Nylon: } \\
\hline TD & None & 9.11 & 8.45 & 15.73 & $>360$ & no failure \\
\hline TD & None & 9.43 & 8.69 & 16.12 & $>360$ & no failure \\
\hline TD & None & 9.13 & 8.35 & 15.59 & $>360$ & no failure \\
\hline TD & None & 9.03 & 8.21 & 15.04 & $>360$ & no failure \\
\hline $\mathrm{TD}$ & None & 8.76 & 8.09 & 15.16 & $>360$ & no failure \\
\hline $\mathrm{MD}$ & None & 9.36 & 8.45 & 16.08 & $>360$ & no failure \\
\hline $\mathrm{MD}$ & None & 9.42 & 8.61 & 17.77 & $>360$ & no failure \\
\hline $\mathrm{MD}$ & None & 8.01 & 7.26 & 14.91 & $>360$ & no failure \\
\hline $\mathrm{MD}$ & None & 8.23 & 7.72 & 16.48 & $>360$ & no failure \\
\hline MD & None & 8.23 & 7.43 & 13.64 & 330 & grip \\
\hline TD & $5 \times 10^{6}$ & 8.93 & 8.13 & 13.94 & 358 & grip \\
\hline $\mathrm{TD}$ & $5 \times 10^{6}$ & 8.16 & 7.49 & 9.80 & 230 & reduced section \\
\hline TD & $5 \times 10^{6}$ & 8.76 & 7.99 & 8.76 & 122 & reduced section \\
\hline $\mathrm{TD}$ & $5 \times 10^{6}$ & 8.72 & 7.75 & 12.40 & 324 & reduced section \\
\hline $\mathrm{TD}$ & $5 \times 10^{6}$ & 9.51 & 8.38 & 7.17 & 251 & shoulder \\
\hline $\mathrm{MD}$ & $5 \times 10^{6}$ & 8.03 & 7.37 & 13.78 & 351 & reduced section \\
\hline $\mathrm{MD}$ & $5 \times 10^{6}$ & 8.82 & 8.03 & 11.28 & 230 & reduced section \\
\hline $\mathrm{MD}$ & $5 \times 10^{6}$ & 7.50 & 6.93 & 9.92 & 265 & shoulder \\
\hline MD & $5 \times 10^{6}$ & 9.74 & 9.06 & 12.73 & 251 & shoulder \\
\hline $\mathrm{MD}$ & $5 \times 10^{6}$ & 8.02 & 7.18 & 13.21 & 371 & reduced section \\
\hline
\end{tabular}

*The irradiated SRS nylon samples did not have a minimum, or lower, yield load. 
Table 2. Effect of $5 \times 10^{6}$ Rad Irradiation on Material Properties

$\begin{array}{lllllll}\begin{array}{l}\text { Material/ } \\ \text { Orientation }\end{array} & \begin{array}{l}\text { Test } \\ \text { Type }\end{array} & \begin{array}{l}\text { Dose } \\ \text { (rad) }\end{array} & \begin{array}{l}\text { Upper } \\ \text { Yield } \\ \text { Load } \\ \text { (lbf) }\end{array} & \begin{array}{l}\text { Lower } \\ \text { Yield } \\ \text { Load } \\ \text { (lbf) }\end{array} & \begin{array}{l}\text { Ultimate } \\ \text { Load } \\ \text { (lbf) }\end{array} & \begin{array}{l}\text { Elongation } \\ \text { to Break } \\ (\%)\end{array} \\ & & & & & \end{array}$

$\begin{array}{llllllc}\text { SRS/MD } & \text { Tensile } & \text { None } & 7.6 \pm 1.2 & 7.3 \pm 0.9 & 9.8 \pm 1.1 & 197 \pm 46 \\ \text { SRS/MD } & \text { Tensile } & 5 \times 10^{6} & 7.6 \pm 0.1 & ----- & 7.6 \pm 0.1 & 27 \pm 7 \\ \text { SRS/TD } & \text { Tensile } & \text { None } & 7.4 \pm 1.0 & 6.9 \pm 1.1 & 8.1 \pm 0.5 & 141 \pm 73 \\ \text { SRS/TD } & \text { Tensile } & 5 \times 10^{6} & 6.8 \pm 0.4 & ------ & 6.8 \pm 0.4 & 7 \pm 2\end{array}$

RFETS/MD Tensile None $\quad 8.7 \pm 0.7 \quad 7.9 \pm 0.6 \quad 15.8 \pm 1.6 \quad>360^{*}$ $\begin{array}{llllll}\text { RFETS/MD Tensile } & 5 \times 10^{6} & 8.4 \pm 0.9 & 7.7 \pm 0.9 & 12.1 \pm 1.6 & 294 \pm 63\end{array}$ $\begin{array}{llllll}\text { RFETS/TD Tensile None } & 9.1 \pm 0.2 & 8.4 \pm 0.2 & 15.5 \pm 0.4 & >360^{*}\end{array}$ RFETS/TD Tensile $\quad 5 \times 10^{6} \quad 8.8 \pm 0.5 \quad 8.0 \pm 0.3 \quad 6.8 \pm 2.7 \quad 257 \pm 92$

*The unirradiated RFETS nylon did not break even when stretched to the maximum extension limit of the instrument, which was $360 \%$ of the initial grip-to-grip separation.

Previous Results [4]

$\begin{array}{lllllll}\text { LDPE/MD } & \text { Tensile } & \text { None } & --- & 4.1 \pm 0.40 & 8.2 \pm 1.0 & 225 \pm 60 \\ \text { LDPE/TD } & \text { Tensile } & \text { None } & --- & 3.4 \pm 0.37 & 4.2 \pm 0.2 & 477 \pm 10\end{array}$

Note: Plus/minus indicates one standard deviation for sample of five measurements. 
Table 3. Significance of the Effect of Irradiation on Material Properties

Material/ Test

Orientation Type
Upper Yield

Load
Effect

$\begin{array}{lll}\text { Lower Yield } & \text { Ultimate } & \text { Elongation } \\ \text { Load } & \text { Load } & \text { to Break }\end{array}$

SRS/MD Tensile NSE

SRS/TD Tensile NSE

RFETS/MD Tensile NSE

RFETS/TD Tensile NSE

\begin{tabular}{lr}
- & $-22 \%$ \\
$-N S E$ & $-17 \%$ \\
$-5 \%$ & $-23 \%$ \\
\hline & $-56 \%$
\end{tabular}

$-86 \%$

$-95 \%$

$>-18 \% *$

$>-29 \% *$

Note: Plus/minus indicates change from measured property of unirradiated sample. "NSE" means that the effect of irradiation is not significant at the $90 \%$ one-sided confidence level according to the Student's t test. ${ }^{11}$

*The unirradiated RFETS nylon did not break even when stretched to the maximum extension limit of the instrument. The listed effect represents a minimal effect that was calculated using the maximum extension limit for the breakage length of the unirradiated samples. 
Figure 1. Tensile Test Sample (Drawing is approximately full-scale.)

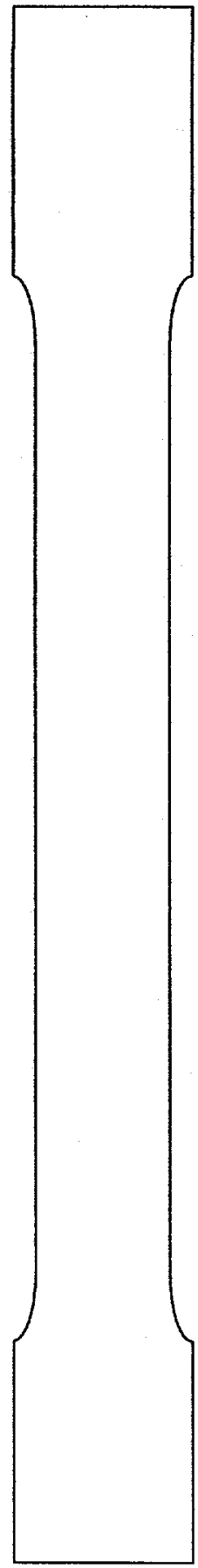


WSRC-TR-98-00293

Revision 0

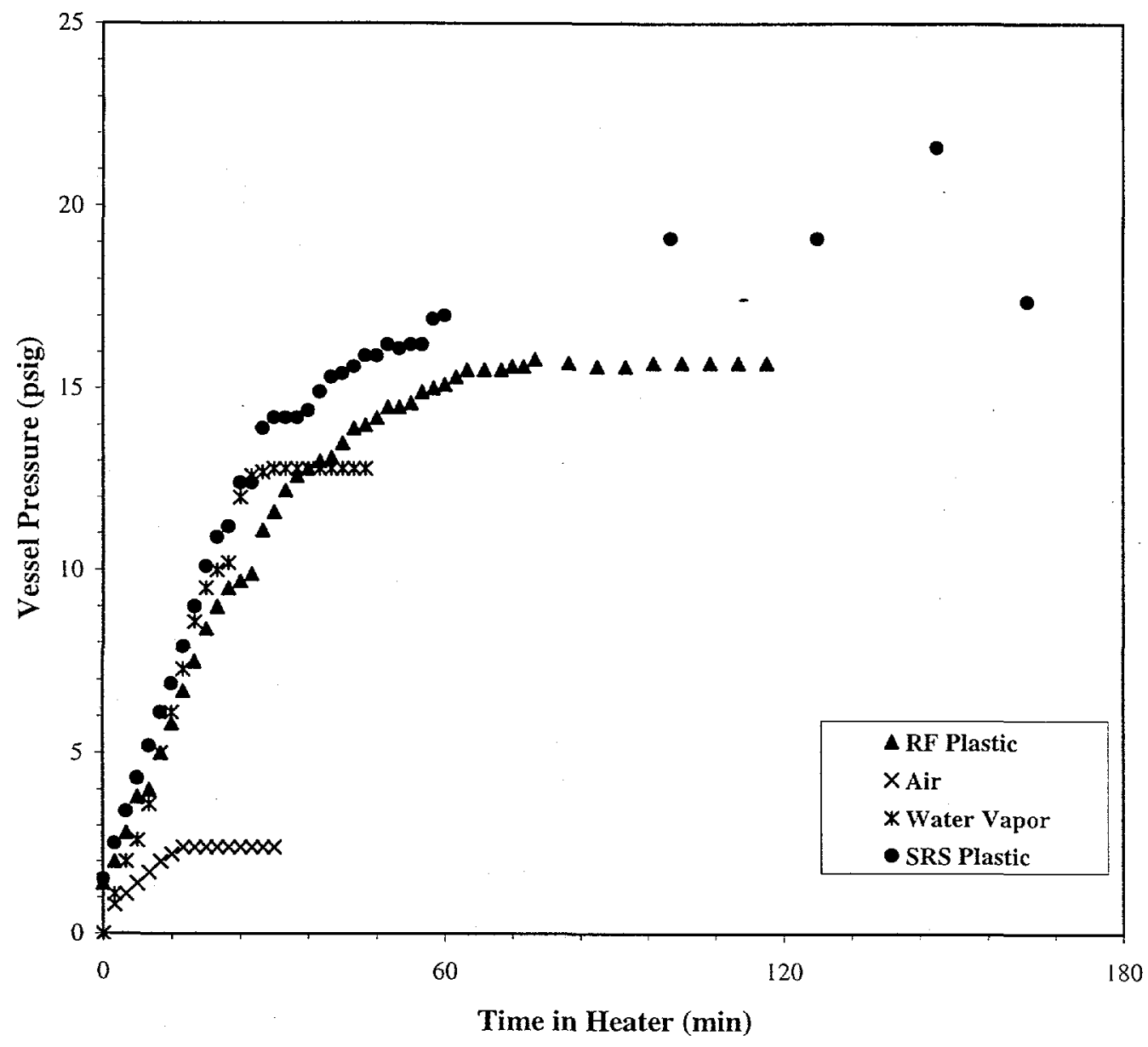

Figure 2. Results of $95^{\circ} \mathrm{C}$ Outgassing Tests for SRS and RFETS Nylon Bag Materials 


\section{Appendix: Calculation of the Expected Dose and Gas Generation for Plutonium Can Bag Material.}

This appendix presents calculations of the expected dose and amount of gas generation for plutonium can bag material. The expected dose is calculated from an estimated activity of $1 \times 10^{9}$ disintegrations $/ \mathrm{min} / 100 \mathrm{~cm}^{2}$ over the exposed surface of the bag, using the formula:

$$
\mathrm{R}=\frac{\left(1.602 \times 10^{-13}\right) \mathrm{A}_{\mathrm{x}} \mathrm{de}_{\alpha} \Delta \mathrm{t}}{\mathrm{m}}
$$

where

$$
\begin{aligned}
& A_{x}=\text { surface area of plastic bag in can, } \mathrm{cm}^{2} \\
& \mathrm{~d}=\text { specific activity at the plastic bag surface, disintegrations } / \mathrm{min} / 100 \mathrm{~cm}^{2} \\
& \mathrm{e}_{\alpha}=\text { energy for one alpha decay particle for } \mathrm{Pu}-239,5.244 \mathrm{Mev} / \text { disintegration } \\
& \mathrm{m}=\text { mass of plastic bag, } \mathrm{gm} \\
& \mathrm{R}=\text { radiation dose, } \mathrm{rad} \\
& \Delta \mathrm{t}=\text { time of exposure, } \mathrm{min}
\end{aligned}
$$

The surface area of the plastic bag was estimated using the dimensions of the inner layer of the double-layer nylon bag sleeving material, which is an 9-inch wide double thickness flat sheet with a seam on either side. The inner can that FB-Line will use to repackage the S/C material is 4.69 inches tall. The minimum bag length needed to enclose this can will be 4.69 inches plus 1.5 inches on each end for heat seals. This gives a typical bag length of slightly less than 8 inches. Using an 8-inch length, the inner surface area of the bag is $930 \mathrm{~cm}^{2}$. The weight of the SRS nylon bag material was measured to be about 17.7 grams/ft, and the weight of the RFETS material is 17 grams/ft. Only the inner layer of the bags would be exposed to the alpha radiation from the plutonium in the can, so the effective weights would be about half of these values.

For the cited bag weights, a surface area of $930 \mathrm{~cm}^{2}$, and a dose of $5.0 \times 10^{6} \mathrm{rad}$, Equation 1 gives an exposure time of between 8 and 9 months.

The amount of gas generation is calculated using the expression

$$
V_{g}=\frac{\left(1 \times 10^{4}\right) A_{x} d e_{\alpha} G V_{M}}{N_{A}}
$$


where

$\mathrm{G}=\mathrm{G}$-value for radiolytic gas generation per accumulated dose, molecules $/ 100 \mathrm{ev}$ $\mathrm{N}_{\mathrm{A}}=$ Avogadro's number, $6.022 \times 10^{23}$ molecules/mole

$\mathrm{V}_{\mathrm{g}}=$ volumetric rate of gas generation by radiolysis, $\mathrm{cm}^{3} / \mathrm{min}$

$\mathrm{V}_{\mathrm{M}}=$ molar volume of gas, $25000 \mathrm{~cm}^{3} /$ mole

For a G-value of 1.6 molecules/100 ev (see discussion in the text), this equation gives a gas generation rate of $1.7 \mathrm{~cm}^{3} /$ year. 


\section{WSRC INTERNAL DISTRIBUTION}

$\underline{\text { Savannah River Technology Center }}$

N. M. Askew, 773-A

F. R. Graham, 773-A

J. R. Knight, 773-A

J. E. Laurinat, 773-A

R. A. Pierce, 773-A

C. R. Wolfe, 773-A

SRTC Records, 773-52A

\section{$\underline{\text { Savannah River Site }}$}

W. E. Harris, 221-F, NSR

W. E. Lloyd, 221-F, NSR

M. E. Logan, 221-F, NSR

W. L. Rigot, 221-F, NSR

T. E. Worth, 221-F, NSR

R. J. Bayer, 703-F

R. T. McNew, 703-F

J. B. Schaade, 703-F

E. R. Selden, 703-F

D. Stimac, 703-F

G. M. Walker, 704-18F

R. L. Yourchak, 703-F 